\title{
The Impacts of Business Agility on the Context of Cloud Computing
}

\author{
Yanliang Zhang ${ }^{1}$, Rongyuan $\mathrm{Ma}^{1}$, Xiyu Huang ${ }^{2}$ \\ ${ }^{1}$ School of Management Engineering, Zhengzhou University, Zhengzhou, China \\ ${ }^{2}$ School of Public Administration, Zhengzhou University, Zhengzhou, China \\ E-mail address: mars19921123@163.com
}

Keywords: Cloud Computing, Cloud Cervices, Business Agility, Business Models

\begin{abstract}
The current state of the market demand is changing all the time, the company's external environment has become difficult to predict the market, so it is particularly important to study what companies will do to respond quickly to these changes in this case. Real-time IT infrastructure support is a commercially successful magic weapon, when the tasks are dealt with, such as high-performance computing, high fluctuations in demand and large-scale data processing, cloud computing services have won the favor of the demanders and heated debate in the industry by its low cost storage, distributed computing power and fast on-demand supply of software and services. Therefore, this paper presents the author's point of view: the core value of the enterprise form the cloud computing is its support on business agility, and then makes further analysis and evaluation on business agility based on the COP model.
\end{abstract}

\section{INTRODUCTION}

In the reality of the rapid expansion of stored data, the reuse of a large number of idle resources, the online processing of massive information, the self-service diffusion of network knowledge, the processing of data becomes more and more important.

Real-time IT infrastructure support is the success of business success magic weapon. Google first proposed "cloud computing service, CCS" in 2007, today it had been known as the fourth IT industry revolution, and been written into E-commerce development special planning and around the "second five" plan, its strategic significance has been widely recognized by the community.

\section{METHODOLOGY}

This article uses the literature research method,which the method of literature retrieval, reading, systematic reading, combing and analyzing the relevant literature, to provide theoretical basis for the study. Firstly, on the basis of literature research, I put forward my own point of view: Cloud computing for the enterprise's core value is the support of its business agility.

And then combined with the three characteristics of business agility (ie, adaptability, interconnection and professionalism), put forward the information system constituted of the interconnection system, adaptive systems and specialized systems corresponding respectively which the enterprise needed to achieve their business agility.

Finally, from the perspective of enterprise management, the paper analyzes the impact of cloud computing on the three dimensions of business agility (ie, enterprise operational agility, customer agility, partner agility) (ie, COP model analysis)

\section{COP MODEL}

\subsection{The impact and value of cloud computing on enterprises}

In order to response the market changes and emerging threats \& opportunities, In general, cloud computing is mainly used as a technology or service to reduce operating costs, it is used in some specific applications to solve operational problems which need cost compression or rapid deployment. On the other hand, cloud computing can also provide strong support for business strategy which need quick response.

In fact, cost savings are a major application of cloud computing, but not the most important advantage of cloud computing. Its core value for the enterprise is the support of enterprises' business agility.

\subsection{COP model}

The upper part of the model shows the information system constituted of the interconnection system, adaptive systems and specialized systems, which the enterprise needed to achieve their business agility. Because the three characteristics of business agility are adaptability, interconnection and professionalism, adaptability is the key, interconnection and professionalism is its two major support.

In the COP model, technical agility as an antecedent variable of business agility has an impact on business agility, and business agility affects organizational performance by influencing business processes. Business agility includes three dimensions: Customer agility, Enterprise Operations Agility, Partner Agility.

There is a positive correlation between the technical agility and the three dimensions of the business agility in the study of the COP model. As shown in Figure 1, this model is very different from the previous research on the agility of the organization. It is not from the technical equipment and other pure technology point of view to study, but from the strategic use of enterprise technology 
and management, technology acceptance and adoption, the response to technological innovation and other aspects of the study. In other words, a company has the technical agility is the prerequisite for improving business agility.

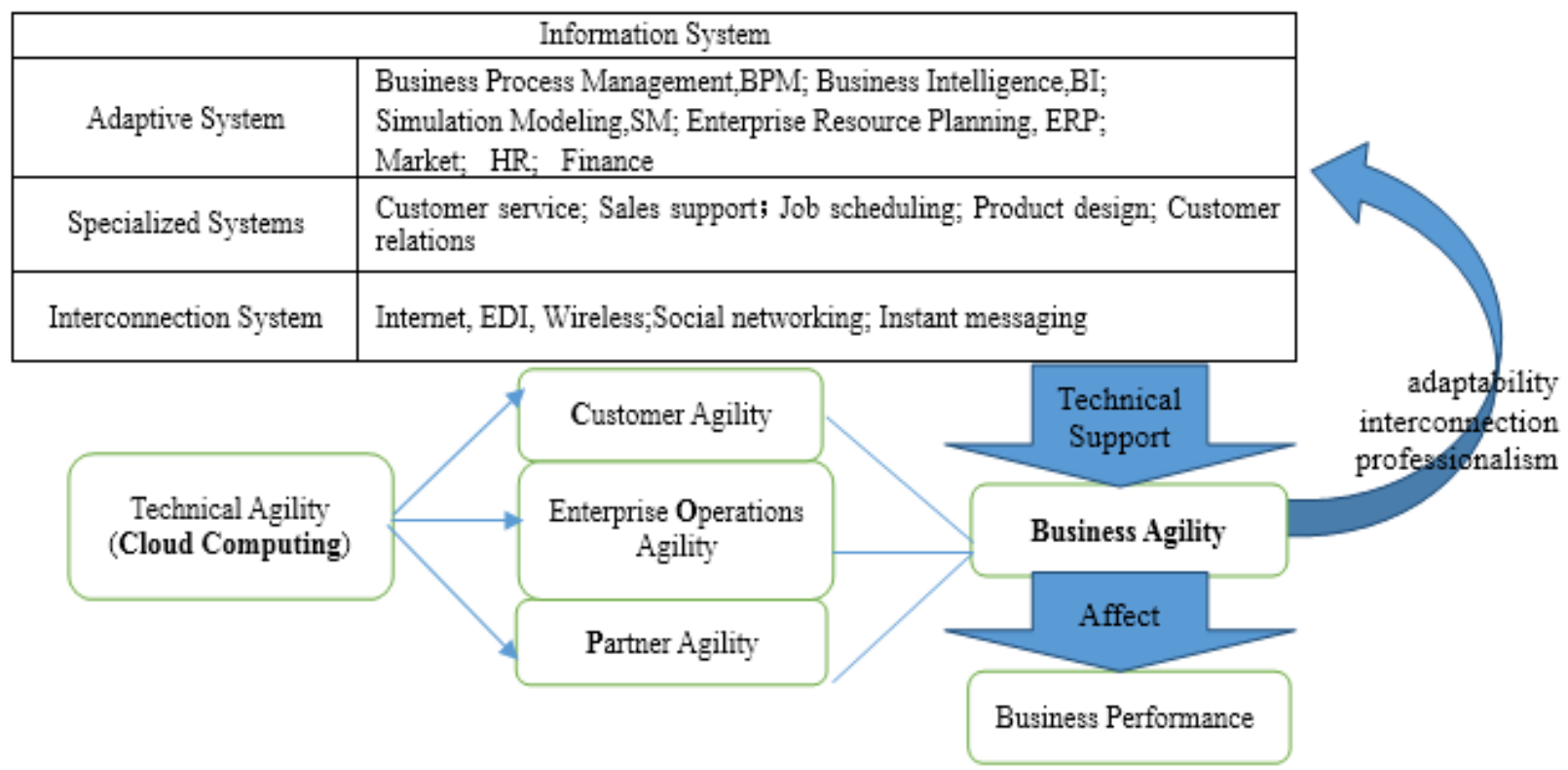

Figure 1 COP Model

\section{ANALYSIS THE IMPACT OF AGILITY BASED ON COP MODEL}

\subsection{Impact on customer agility}

In many cases, corporate purchases manufacturing resources form external to meet the customization needs of customers, which will be detrimental to the maintenance and expansion of resources, cause serious waste of manufacturing resources, these are not conducive to changes in the external market environment, and extends the business response from environmental changes. In the traditional manufacturing model, the enterprise completely put their focus on the production, equipment, orders, etc., ignoring the manufacturing services. In cloud computing mode, the corporate adjusts the processing technology and equipment timely through the virtual resource layer interface to the needs of users for resource reorganization and on-demand deployment. So that the manufacturing enterprises can form the production concept that production is service, which can make organized production truly based on user needs to, this change on the transformation and upgrading of manufacturing enterprises plays a vital role in improving the efficiency.

\subsubsection{Cloud computing drives the agile value chain for customer needs}

The key to enabling customers to demand agility in cloud computing is that it intelligently analyzes current customer needs and changes in internal and external environments. The key to enhancing the competitiveness of modern enterprises is the need for accurate on-demand services, rather than limited to the improvement of production efficiency. That is to say, in the cloud computing mode, the enterprise will implement the modular management. Cloud computing model has been able to agile response to customer needs, is that all aspects of business forces in the virtual interface can be a free combination of production, the formation of customer demand for the agile value chain.

\subsubsection{Cloud computing enables rapid and intelligent identification of market opportunities}

In the cloud computing model, enterprises meet the changing market environment in the dynamic needs through the establishment of an on-demand distribution of resources. The customer relationship management system of cloud computing server is an intelligent identification system based on unified communication technology to meet the needs of customers. Cloud computing customer relationship management system can be scattered in different regions of the customer and related business implementation of integrated management, so that manufacturing products can be monitored in the pre-sale, sale, after-sale, by the manufacturing products and customers, which is effective to achieve the integration of customer relationship management. In addition, the customer relationship management system can also tap the enterprise market opportunities through intelligent analysis of data and reports, Provide technical support for rapid decision making.

\subsubsection{Cloud computing can increase customer engagement}

Cloud computing service platform itself is an open nature of the service platform, users participate in the service or manufacturing process will be more smooth, the upstream and downstream supply chain users can communicate through this open platform, so the flow of information is more convenient, customers can not only have a comprehensive understanding to the terminal manufacturing products or services, but have a more in-depth understanding through the entire manufacturing and transfer process. 


\subsection{Impact on business operations agility}

\subsubsection{Improve business process agility}

McKinsey survey results show that enterprises can enhance business agility to make business processes more smoothly, reduce the risk of all aspects of the enterprise, so that business income can continue growing. Private cloud application services in cloud computing services are able to make all aspects of resources and knowledge in a wide area to achieve free trade, each enterprise can not only publish the necessary resources and capabilities, and make a comprehensive collaborative management on all aspects of business processes, and a implementation of the enterprise to track the process. Cloud computing service platform can form a corresponding relationship between the data center and enterprise business information system. These can make process collaboration more closely, complete business progress quickly.

\subsubsection{Improve resource allocation efficiency}

The service resource provider in the cloud computing mode forms a shared resource pool which can allocate the resources dynamically in real time through the gathering of autonomous manufacturing resources and capabilities, this powerful virtual resource pool can form a dynamic resource scheduling mechanism, in accordance with the needs of cloud demand to provide services. In addition, cloud computing in the process of participating in business services, you can quickly adjust the required types of resources and quantity, control and access according to customer needs to share resources multi-scaled and multi-granularity.

\subsection{Impact on partner agility}

\subsubsection{Strengthen resource sharing and collaboration among partners}

Virtual private cloud platform is a shared service network after the formation of the package which gather the intention and business resources who want to cooperate with each over. In order to achieve the sharing of resources between collaborative enterprises more smoothly, cloud computing service platform will provide the further corresponding integrated services for enterprises.

\subsubsection{Cloud computing platform make the supply chain more agile}

Users with different only needs to pass the demand to the cloud platform, then cloud computing platform will be a detailed decomposition of the demand, and match the demand through the scheduling of cloud resources, then it will decompose the corresponding manufacturing processto the various partners, eventually, the corresponding manufacturing information reacts again to the cloud platform, so we achieve a closed-loop operation..In this way upstream and downstream partners will get accurate information and form a truly agile supply chain.

\subsubsection{Help enterprises to establish a network of partners}

The synergistic thinking of cloud computing is expressed in: it can make enterprises with different core manufacturing capacity into cooperative partnership. make up the deficiencies on manufacturing capacity and manufacturing resources, enhance the comprehensive competitiveness of enterprises, improve organizational flexibility, and also ease the competitive relationship between partners, strengthen the organization and collaboration to some extent.

\section{CONCLUSIONS}

The process of enterprise development is in fact the pursuit of agile process from a certain point of view, and cloud computing for the enterprise's core value is the support of its business agility. So this article will study the impact of cloud computing in the context of enterprise agility.

As a new business computing model, it will be distributed in a large number of computing tasks in the pool of resources, so that a variety of applications can be based on the need to obtain computing power, storage space and a variety of information services. It provides a way for enterprises to reduce costs and improve service usage, to standardize the infrastructure resources used by enterprises, and to benefit from this standardization and agile establishment and deployment of business systems. Application is a powerful reason to drive business agility. Without the need for substantial capital investment, companies can experiment with new products and explore new markets. In this way, more business opportunities came into being. So if enterprises want to catch a new era of express, they should:1. create cloud needs; 2 . can not just focus on the short-term benefits, migration to cloud computing is a long-term strategy 3 . the expected return on investment is based on the study of knowledge and industry experience, seek industry cloud computing analysts, media, products and service providers, and set up their own business cloud plan.

\section{ACKNOWLEDGMENTS}

Thank the organizers to give us the opportunity to learn and exchange diffrernt opinions , thank my Advisor. ZHANG's help and guidance in the collection of literature and writing, thank my schoolmate HUANG's help for the information collecting. It is you who make me more powerful, I will forward on with this force! Finally, I wish the this meeting will be held successfully! Also wish the development of this industry in China getting better and better!

\section{REFERENCES}

[1] Bhattacherjee A, Park S C. Why end--users move to the cloud: a migration--theoretic analysis [J]. European Journal of In-formation Systems, 2014, 3 ( 23) : 357-372.

[2] Cegielski C G, et al. Adoption of cloud computing technologies in supply chains: An organizational information processing theory [J]. International Journal of Logistics Management, 2012, 23 (2): 184-211. 
[3] E Overby, A Bharadwaj, V Sambamurthy. A Framework for Enterprise Agility and the Enabling Role of Digital Options [J] .Business Agility and Information Technology Diffusion, 2016, (180-191).

[4] Gangwar H, Date H, Ramaswamy R. Understanding determi-nants of cloud computing adoption using an integrated TAM-TOEmodel [J], Journal of Enterprise Information Management, 2015, 28( 3) : 107-130.

[5] Jackson, M., Johansson, C. Agility Analysis from a Production System Perspective [J]. Integrated Manufacturing Systems, 2013, (6).

[6] Lin, C T. Chiu, H. Chu, P Y. Agility Index in the Supply Chain [J]. International Journal of Production Economics, 2016, (100): 2.

[7] Liu S,Chan F T S, Ran W. Decision making for the selection of cloud vendor: an improved approach under group decision--making with integrated weights and objective / subjective attributes [J].Ex-pert Systems with Applications, 2016, 55 ( 15) : 37-47.

[8] Rick Dove. Agile Enterprise (upper and lower) (Zhang Shensheng translation) [J] China Construction Machinery, 1996 (3, 4): 22-26.

[9] Yang $H$, ate M. A descriptive literature review and classification of cloud computing research $[\mathrm{J}]$. Journal of the Association for Information Systems, 2015, 31 (2): 35-60.

[10] Yang Shanlin, Luo He, Multi-source information service system based on cloud computing research summary C[J]. Journal of Management Science, 2015, 15 (5): 83-96. 